\title{
PERBANDINGAN ANALISA NERACA KEUANGAN SARANA PERAIRAN NELAYAN DI KABUPATEN BINTAN DAN KABUPATEN LINGGA
}

\author{
Inge Lengga Sari Munthe ${ }^{1}$, Rizki Yuli Sari ${ }^{2}$ \\ Universitas Maritim Raja Ali Haji \\ Email: ingemunthe@umrah.ac.id
}

\begin{abstract}
Abstrak
Kabupaten Bintan 98\% dari total luas daerahnya adalah perairan. Jadi wajar bahwa banyak penduduk Bintan yang menjadi nelayan. Begitu juga dengan penduduk kabupaten Lingga. Dalam menjalankan profesinya, nelayan memerlukan sarana perairan. Sarana itu alat tangkap ikan yang bisa berupa motor, kelong ataupun pukat cincin. Tujuan penelitian ini adalah untuk melihat net present value atau sarana yang bisa menguntungkan dan internal rate of return atau berapa imbal hasil yang diperoleh dengan investasi yang dipakai. Metode pengambilan data, adalah dengan data primer. Data primer ini bisa berupa wawancara dan observasi. Dari hasil penelitian, untuk nelayan Lingga, dari hasil Net Present Value usaha dengan menggunakan pukat cincin dikatakan usaha yang layak rata-rata setelah 2 tahun 8 bulan. Sementara untuk imbal hasil yang diperoleh dengan investasi yang dipakai, pada tahun 3 baru bisa melebihi bunga deposito tabungan. Dari hasil penelitian, untuk nelayan di Bintan, dalam hal ini Telok Sebong, dari hasil Net Present Value usaha dengan menggunakan kelong apung dikatakan usaha yang layak pada tahun ke 3 . Sementara untuk imbal hasil yang diperoleh dengan investasi yang dipakai, pada tahun 3 baru bisa melebihi bunga deposito tabungan.
\end{abstract}

Kata kunci: Bintan, Lingga, Nelayan, Neraca Keuangan

\begin{abstract}
Bintan district has $98 \%$ of their district is waters. Fisherman is the main job in Bintan. So is people of Lingga district. Fisherman needs water facitilities in order to do their job. The fishing gear could be machine motor, kelong or purse seine. The main object of this research is to know net present value of profitable fishing gear and internal rate of return that can be obtained of investment. Data used are primer data's. It can be obtained by interview and observation. As for the result, fisherman in Lingga district, Net Present Value with purse seine worth it average after 2 years and 8 months. For Internal Rate of Return with purse seine, in the $3^{\text {rd }}$ year would be exceeded of deposit interest. Fisherman in Bintan district, in Telok Sebong, Net Present Value with floating kelong it called worth it after the $3^{\text {rd }}$ year. Meanwhile for the Internal Rate of Return with floating, same as fisherman in Lingga District, in the $3^{\text {rd }}$ year that would be exceeded of deposit interest.
\end{abstract}

Keywords: Bintan, Lingga, Fisherman, Balance Sheet 


\section{PENDAHULUAN}

Nelayan menurut UU no.45/2009 artinya orang yg mata pencahariannya melakukan penangkapan ikan. Dari definisi diatas, nelayan adalah orang-orang yang sehari-harinya bekerja menangkap ikan atau binatang laut di perairan. Perairan yang menjadi daerah aktivitas nelayan ini bisa merupakan perairan tawar dan laut. Dalam bekerja, nelayan menggunakan alat tangkap di perairan. Ada nelayan yang bekerja menggunakan alat tangkap milik orang lain. Ada nelayan yang memiliki alat tangkap sendiri, tapi mempekerjakan nelayan lain. Selain itu, ada juga nelayan yang mempunyai dan menggunakan sendiri alat tangkap di perairan.

Luas wilayah kabupaten Bintan mencapai $88.038,54 \mathrm{~km} 2$, namun luas daratannya hanya 2,21\%, 1.946,13 km2 saja. Selebihnya sebesar $86.092,41 \mathrm{~km} 2$ adalah perairan. Jumlah nelayan di Bintan, belum diketahui pasti. Hal ini karena dalam statistik kabupaten Bintan, jumlah tenaga kerja untuk profesi nelayan, masih bergabung dengan profesi di bidang pertanian dan kehutanan. Luas wilayah kabupaten Lingga adalah 45.508,66 km2. Luas lautannya adalah $43.273,15 \mathrm{~km} 2$ atau sekitar $95,09 \%$ dari seluruh luas kabupaten Lingga. Luas daratannya hanya $4,91 \%$ atau sekitar $2.235,51 \mathrm{~km} 2$. Dari luas itu, banyak penduduk kabupaten Lingga berprofesi sebagai nelayan.

Dalam melaksanakan pekerjaannya, nelayan di Bintan menggunakan beberapa peralatan seperti : kelong apung, kapal motor yang berbahan fiber dan berbahan kayu. Sementara nelayan di kabupaten Lingga, lebih banyak memakai pukat cincin. Bila nelayan dapat menggunakan peralatan ikan ini dengan tepat, maka nelayan mendapatkan hasil yang optimal. Peralatan ikan ini juga harus disesuaikan dengan kondisi dari nelayan itu sendiri, perairan tempat mengambil ikan dan kondisi alam. Nelayan tidak bisa melaut setiap hari. Ada saatnya nelayan tidak melaut.

Pukat cincin adalah alat pengkapan ikan yang digolongkan dalam kelompok jaring lingkar. Jaring berbentuk empat persegi panjang, dilengkapi dengan tali kerut yang dilewatkan melalui cincin yang diikatkan pada bagian bawah jaring yang dapat dikuncupkan sehingga jarring akan berbentuk seperti mangkok.(Tamarol, Solapeil, 2017). Kelong adalah alat tangkap tradisional yang terbuat dari kayu. Kelong menggunakan cahaya lampu untuk menarik perhatian ikan. Cahaya ini dapat memikat perhatian ikan dengan maksimal. Kelong dioperasikan pada malam hari. (Rambe, et.al). Untuk itu setiap sarana peralatan yang digunakan nelayan akan dinilai melalui beberapa instrumen perhitungan. Tujuannya untuk dapat mengetahui peralatan yang mana yang dapat menguntungkan nelayan (net present value) dan imbal hasil dari investasi (internal rate of return).

Dari latar belakang diatas, maka perumusan masalah adalah sebagai berikut: (1) Berapa Net Present Value dari peralatan-peralatan perikanan di Bintan dan Lingga dan (2) Berapa Internal rate of return dari peralatan-peralatan perikanan di Bintan dan Lingga. Dari perumusan masalah diatas, maka tujuan penelitian adalah untuk mengetahui Net Present Value dan Internal Rate of Return dari peralatan-peralatan perikanan di Bintan dan Lingga. Penelitian ini diharapkan bermanfaat bagi para nelayan atau pelaku industri penangkapan ikan. Tujuannya : agar mengetahui sarana perairan yang mana yang memberikan keuntungan yang paling banyak dengan waktu pengembalian modal yang paling cepat. Selain itu juga untuk peneliti dan instansi terkait. Untuk instansi terkait, agar dapat menjadi dasar keputusan untuk memberi sarana perairan yang dapat menguntungkan nelayan.

\section{LANDASAN TEORI}

\section{Arus Kas Operasi}

Laporan arus kas adalah laporan yang terdiri dari aktivitas-aktivitas yang menerangkan darimana arus kas masuk dan kemana arus kas keluar. Sehingga laporan arus kas adalah satusatunya laporan keuangan yang bersifat basis kas (cash basis). Tidak ada transaksi yang 
bersifat non-kas. Dengan laporan arus kas dapat membuktikan apakah nilai kas di laporan posisi keuangan benar atau tidak.

Menurut PSAK no.2 (2016), laporan arus kas melaporkan arus kas selama periode tertentu dan diklasifikasikan menurut :

1. Aktivitas operasi

2. Aktivitas investasi

3. Aktivitas pendanaan.

Transaksi harus bisa diidentifikasi untuk masuk ke aktivitas yang tepat. Dengan adanya aktivitas-aktivitas ini, laporan arus kas dapat menyediakan informasi yang memungkinkan pengguna untuk mengevaluasi perubahan dalam aset neto, struktur keuangan seperti likuiditas dan solvabilitas. Informasi dalam arus kas berguna untuk menilai kemampuan dalam menghasilkan kas.. Dari kas yang dihasilkan di aktivitas operasi dapat dilihat apakah kas yang dihasilkan bisa untuk membayar pinjaman, membayar dividen, melakukan investasi baru tanpa bantuan dana dari pihak luar.

Aktivitas operasi adalah aktivitas yang terdiri dari transaksi yang merupakan penghasil utama entitas dan yang menyebabkan terjadinya laba atau rugi. Sumber data untuk aktivitas operasi adalah dari laporan laba rugi yang dihubungkan dengan kenaikan dan penurunan dari aset lancar selain kas dan liabilitas lancar.

Aktivitas operasi (PSAK no.2), adalah aktivitas penghasil utama pendapatan entitas dan aktivitas lain yang bukan merupakan aktivitas investasi dan aktivitas pendanaan. Berikut arus kas dari aktivitas operasi :

a. Penerimaan kas dari:

1) Penjualan barang dan pemberian jasa

2) Royalti, fees, komisi dan pendapatan lain

3) Premi, klaim, anuitas dan manfaat polis lain

4) Restitusi pajak penghasilan

5) Kontrak yang dimiliki untuk tujuan diperdagangkan atau diperjualbelikan

b. Pembayaran kas kepada:

1) Pemasok barang dan jasa

2) Karyawan, seperti gaji

3) Premi, klaim, anuitas dan manfaat polis lain

4) Restitusi pajak penghasilan

\section{Net Present Value}

Net Present Value (NPV) atau nilai sekarang bersih adalah nilai sekarang dari arus kas bersih saat ini dikurangi dengan arus kas keluar awal dalam investasi tersebut. NPV ini merupakan alat ukur dari suatu investasi apakah proyek itu menguntungkan atau tidak. Suatu proyek itu menguntungkan / diterima atau tidak dapat dilihat dari skema sebagai berikut (Van Horne, 2007) :

1. Bila NPV nilainya adalah 0 (nol) atau lebih, maka proyek itu diterima atau menguntungkan. Bila NPV nilainya dibawah 0 (nol), maka proyek itu ditolak atau tidak menguntungkan.

2. Bila NPV dari arus kas yang masuk melebihi dari nilai sekarang dari arus kas yang keluar, maka proyek itu diterima atau menguntungkan. Bila tidak, maka proyek itu ditolak atau tidak menguntungkan.

Pada NPV, nilai waktu uang dapat memperbolehkan perbandingan antara keuntungan dan biaya dalam tahap yang logis. Dengan NPV, penerimaan dari suatu proyek dapat meningkatkan nilai dari suatu usaha ( Scott, Et.Al,2000).

Dalam menghitung NPV, salah satu elemennya adalah arus kas. Arus kas yang digunakan adalah arus kas operasi, arus kas yang berhubungan dengan operasional usaha. 


\section{Internal rate of return}

Internal rate of return (IRR) atau tingkat pengembalian internal adalah suatu proposal investasi di tingkat diskonto yang menyamakan nilai sekarang dari arus kas bersih yang diharapkan dengan arus kas keluar awalnya atau investasi awal. Kriteria penerimaan yang bisaanya digunakan untuk metode IRR adalah membandingkan IRR dengan tingkat pengembalian yang diminta, atau disebut juga sebagai titik toleransi atau tingkat batas. Jika IRR melebihi tingkat pengembalian yang diminta, proyek tersebut akan diterima, jika tidak proyek tersebut akan ditolak. Jika tingkat pengembalian yang diminta adalah pengembalian yang diharapkan investor perusahaan dari proyek tersebut, menerima suatu proyek dengan IRR yang melebihi tingkat pengembalian yang diminta seharusnya menghasilkan peningkatan harga pasar saham. Hal ini disebabkan karena perusahaan menerima proyek dengan pengembalian yang lebih besar daripada yang diminta untuk mempertahankan harga pasar sekarang per lembar saham. (Van Horne,Wachowicz,2007)

\section{METODE PENELITIAN}

\section{Jenis dan Sumber Data Penelitian}

Data yang diambil dari penelitian ini adalah data primer dan sekunder. Pengambilan data primer adalah dengan cara observasi dan wawancara kepada pihak nelayan, pengguna sarana perikanan. Data sekunder yang dipakai dapat berupa jumlah nelayan dari masing-masing kabupaten.

\section{Metode Analisis}

Data yang diminta dengan wawancara ini adalah data-data mengenai :

1. Investasi awal dari sarana perikanan.

2. Kas masuk berupa penjualan ataupun pendapatan dengan menggunakan sarana tersebut.

3. Biaya yang keluar dengan menggunakan sarana tersebut.

Setelah data-data tersebut diperoleh, maka akan dihitung dengan menggunakan rumus NPV dan Internal rate of return itu.

\section{Operasional variable penelitian}

\section{Net Present Value}

Net present value (NPV) merupakan kombinasi antara present value penerimaan dan present value pengeluaran. Berikut rumus Net Present Value (Van Horne) :

Dimana :

$$
\mathrm{NPV}=\sum_{t=1}^{n} \frac{C F_{t}}{(1+k)^{t}}-1 \mathrm{O}
$$

NPV $=$ net present value

$\mathrm{CF}=$ Arus kas bersih, dalam hal ini adalah arus kas operasi

$\mathrm{T}=$ periode

$\mathrm{IO}=$ investasi awal

$\mathrm{K}=$ bunga

\section{Internal rate of return}

Berikut rumus Internal Rate of Return (Van Horne, Wachowicz, 2007)

Dimana :

$$
\mathrm{ICO}=\sum_{t=1}^{n} \frac{C F_{t}}{(1+i r r)^{t}}
$$

ICO = initial cash outflow (investasi awal)

$\mathrm{CF}=$ Arus kas bersih, dalam hal ini adalah arus kas operasi 
$\mathrm{T}=$ periode

$\mathrm{IRR}=$ internal rate of return

\section{HASIL DAN PEMBAHASAN}

\section{Net Present Value dari nelayan di Lingga}

Untuk Lingga, terdapat 15 nelayan di Kecamatan Senayang yang menggunakan pukat cincin untuk melaut. Arus kas bersih berasal dari pendapatan dikurangi total biaya yang dikeluarkan secara tunai. Untuk investasi awal adalah kapal, mesin kapal, alat tangkap dan asset tetap lainnya yang mendukung untuk menangkap ikan. Untuk tingkat bunga yang dipakai, adalah bunga deposito berjangka waktu 1 bulan dari Bank Rakyat Indonesia (BRI). Kenapa BRI? Karena di Lingga, terdapat Bank Rakyat Indonesia. Bunga deposito berjangka waktu 1 bulan adalah $4 \%$ setahun. Tapi untuk pendapatan bunga bersih bila dikurangi dengan tarif pajak $20 \%$, maka bunga bersih menjadi 3,2\%. Disini dibuat proyeksi untuk 4 tahun, dengan asumsi arus kas bersihnya tetap setiap tahun. Nilai arus kas bersih diambil dari arus kas bersih di tahun pertama. Berikut hasilnya NPV nya.

\begin{tabular}{|c|c|c|c|c|c|}
\hline \multirow[t]{2}{*}{ Nelayan } & \multicolumn{4}{|c|}{ Tahun ke } & \multirow{2}{*}{$\begin{array}{l}\text { Layak di } \\
\text { Tahun ke }\end{array}$} \\
\hline & $1(\mathrm{Rp})$ & 2 (Rp) & $3(\mathrm{Rp})$ & $4(\mathrm{Rp})$ & \\
\hline 1 & -91.035 .271 & 52.535 .202 & 191.653 .878 & 326.458 .797 & 2 \\
\hline 2 & -82.427 .713 & 45.621 .983 & 169.701 .147 & 289.932 .894 & 2 \\
\hline 3 & -104.209 .496 & -7.174 .124 & 86.852 .399 & 177.963 .371 & 3 \\
\hline 4 & -167.737 .984 & -83.860 .062 & -2.583 .006 & 76.173 .831 & 4 \\
\hline 5 & -106.381 .395 & -17.797 .476 & 68.039 .655 & 151.215 .170 & 3 \\
\hline 6 & -162.472 .868 & -52.465 .958 & 54.129 .886 & 157.420 .432 & 3 \\
\hline 7 & -105.644 .767 & -10.024 .387 & 82.631 .020 & 172.413 .392 & 3 \\
\hline 8 & -233.678 .682 & -119.249 .111 & -18.057 .665 & 79.996 .061 & 4 \\
\hline 9 & -205.832 .946 & -112.841 .614 & -22.733 .735 & 64.580 .102 & 4 \\
\hline 10 & -102.412 .403 & 1.160 .850 & 101.522 .529 & 198.772 .218 & 2 \\
\hline 11 & -63.332 .171 & 50.590 .145 & 160.979 .985 & 267.946 .885 & 2 \\
\hline 12 & -101.004 .264 & -13.847 .542 & 70.606 .645 & 152.442 .098 & 3 \\
\hline 13 & -105.010 .465 & 19.397 .999 & 139.948 .836 & 256.761 .663 & 2 \\
\hline 14 & -72.680 .233 & 61.350 .550 & 191.225 .339 & 317.073 .003 & 2 \\
\hline 15 & -70.209 .690 & 45.817 .742 & 158.247 .425 & 267.190 .915 & 2 \\
\hline
\end{tabular}

Dari hasil diatas, ada 7 nelayan yang usahanya layak di tahun ke 2, 5 nelayan yang usahanya layak di tahun ke 3 dan 3 nelayan yang usahanya layak di tahun ke 4 . Bila dirata-ratakan, maka usaha dengan menggunakan pukat cincin akan layak setelah 2 tahun 8 bulan berjalan.

\section{Net Present Value dari nelayan di Bintan}

Sampel yang diambil adalah nelayan yang ada di Telok Sebong, Bintan. Terdapat 20 nelayan. Untuk investasi awal terdiri dari kelong apung, jarring, beberapa jenis mesin dan asset tetap lainnya untuk mendukung kegiatan melaut. Bunga yang dipakai juga bunga deposito dari Bank Rakyat Indonesia. NPV dibuat proyeksi untuk 4 tahun. Berikut hasilnya. 


\begin{tabular}{crrrrr}
\hline \multirow{2}{*}{ Nelayan } & \multicolumn{4}{c}{ Tahun ke } & \multicolumn{1}{c}{$\begin{array}{c}\text { Layak di } \\
\text { Tahun ke }\end{array}$} \\
\cline { 2 - 5 } & $\mathbf{1}(\mathbf{R p})$ & $\mathbf{2}(\mathbf{R p})$ & \multicolumn{1}{c}{$\mathbf{3}(\mathbf{R p})$} & $\mathbf{4}(\mathbf{R p})$ & 3 \\
\hline 1 & -122.083 .411 & -7.033 .421 & 104.449 .127 & 212.474 .851 & 3 \\
\hline 2 & -146.338 .256 & -52.610 .791 & 38.210 .397 & 126.215 .423 & 3 \\
\hline 3 & -140.582 .403 & -41.248 .491 & 55.005 .299 & 148.274 .476 & 3 \\
\hline 4 & -132.615 .388 & -27.286 .306 & 74.776 .758 & 173.675 .076 & 3 \\
\hline 5 & -137.743 .295 & -36.050 .751 & 62.488 .536 & 157.972 .341 & 3 \\
\hline 6 & -128.795 .581 & -19.009 .323 & 87.372 .710 & 190.456 .076 & 3 \\
\hline 7 & -122.647 .364 & -7.417 .097 & 104.240 .138 & 212.435 .134 & 3 \\
\hline 8 & -139.588 .217 & -39.533 .195 & 57.419 .346 & 151.365 .607 & 3 \\
\hline 9 & -128.506 .860 & -17.258 .663 & 90.539 .977 & 194.996 .025 & 3 \\
\hline 10 & -123.177 .403 & -8.702 .988 & 102.221 .834 & 209.707 .126 & 3 \\
\hline 11 & -145.187 .054 & -49.588 .270 & 43.046 .212 & 132.808 .306 & 3 \\
\hline 12 & -138.505 .891 & -37.431 .174 & 60.509 .444 & 155.413 .143 & 3 \\
\hline 13 & -134.973 .488 & -32.094 .117 & 67.595 .197 & 164.193 .369 & 3 \\
\hline 14 & -126.180 .116 & -14.227 .710 & 94.253 .305 & 199.370 .567 & 3 \\
\hline 15 & -122.805 .310 & -5.790 .107 & 107.596 .718 & 217.467 .673 & 3 \\
\hline
\end{tabular}

Dari hasil diatas, maka semua nelayan yang berusaha usahanya dikatakan layak di tahun ke 3 .

Internal Rate of Return dari nelayan di Lingga

Data yang dipakai, sama dengan data dalam menghitung NPV di Lingga. IRR juga diproyeksikan untuk 4 tahun. Berikut hasilnya:

\begin{tabular}{ccccc}
\hline Nelayan & \multicolumn{5}{c}{ Tahun ke } \\
\cline { 2 - 5 } & $\mathbf{1}(\%)$ & $\mathbf{2}(\%)$ & $\mathbf{3}(\%)$ & $\mathbf{4}(\%)$ \\
\hline 1 & -36 & 18 & 41 & 52 \\
\hline 2 & -36 & 18 & 41 & 51 \\
\hline 3 & -49 & 1 & 24 & 36 \\
\hline 4 & -65 & -21 & 3 & 15 \\
\hline 5 & -52 & -3 & 20 & 32 \\
\hline 6 & -58 & -10 & 13 & 25 \\
\hline 7 & -50 & 0 & 23 & 35 \\
\hline 8 & -66 & -23 & 0 & 13 \\
\hline 9 & -67 & -24 & -1 & 12 \\
\hline 10 & -47 & 4 & 27 & 38 \\
\hline 11 & -33 & 22 & 45 & 56 \\
\hline 12 & -51 & -2 & 22 & 33 \\
\hline 13 & -43 & 9 & 32 & 43 \\
\hline 14 & -32 & 23 & 46 & 56 \\
\hline 15 & -35 & 19 & 43 & 53 \\
\hline
\end{tabular}

Bila dilihat di tahun pertama, umumnya bunganya masih negative. Untuk pembandingnya adalah bunga $3,2 \%$. Sehingga bila hanya dilakukan 1 tahun saja, maka usaha ini tidak layak. Mulai tahun kedua, bila bunga deposito tadi memakai nilai akan datang menjadi 6,5\%. Ada 6 nelayan yang IRR nya melebihi $6,5 \%$. Untuk tahun ke 3, nilai akan datang bunga deposito menjadi 9,9\%. Terdapat 12 nelayan yang IRR nya melebihi 9,9\%. Mulai tahun ke 4, dengan nilai akan datang bunga deposito $13,4 \%$, maka semua nelayan IRR nya sudah melebihi dari $13,4 \%$. 
Artinya bila investasi awal hanya ditabung menjadi deposito setelah 4 tahun hanya akan mendapat bunga $13,4 \%$. Sehingga akan lebih baik bila nilai uangnya dibuat untuk investasi di pukat cincin, karena imbal hasilnya akan lebih tinggi setiap tahunnya.

\section{Internal Rate of Return dari nelayan di Bintan}

Data yang dipakai, sama dengan data dalam menghitung NPV di Bintan. IRR juga diproyeksikan untuk 4 tahun. Berikut hasilnya.

\begin{tabular}{ccccc}
\hline Nelayan & \multicolumn{5}{c}{ Tahun ke } & $\mathbf{4}(\%)$ \\
\cline { 2 - 5 } & $\mathbf{1}(\%)$ & $\mathbf{2}(\%)$ & 25 & 36 \\
\hline 1 & -49 & 1 & 11 & 23 \\
\hline 2 & -59 & -12 & 15 & 27 \\
\hline 3 & -56 & -9 & 19 & 30 \\
\hline 4 & -54 & -7 & 16 & 28 \\
\hline 5 & -55 & -2 & 21 & 33 \\
\hline 6 & -52 & 1 & 24 & 36 \\
\hline 7 & -49 & -8 & 15 & 27 \\
\hline 8 & -56 & -2 & 22 & 33 \\
\hline 9 & -51 & 1 & 24 & 36 \\
\hline 10 & -49 & -11 & 12 & 24 \\
\hline 11 & -58 & -8 & 16 & 28 \\
\hline 12 & -56 & -6 & 17 & 34 \\
\hline 13 & -55 & -1 & 22 & 36 \\
\hline 14 & -51 & 2 & 25 & \\
\hline 15 & -49 & &
\end{tabular}

Bila dilihat dari imbal hasil diatas, maka setelah tahun ke3, imbal hasilnya melebihi dari nilai sekarang bunga deposito sebesar 9,9\%. Sehingga bila investasi awal itu di tabung di deposito, maka selama 2 tahun pertama, imbal hasilnya masih lebih besar bila dibandingkan investasi awal itu dipakai untuk usaha ini. Nelayan dapat menikmati imbal hasil yang lebih besar dari bunga sekarang deposito, mulai dari tahun ke 3 berusaha. 


\section{DAFTAR PUSTAKA}

Amry,et.al, 2017, “Analisis Kelayakan Usaha Penangkapan Ikan menggunakan alat tangkap payang di Pantai Melabero Kota Bengkulu", Jurnal Enggano, vol.2, no.2, Sep 2017, Universitas Bengkulu.

Badan Pusat Statistik, "Bintan dalam Angka tahun 2016".

Badan Pusat Statistik, "Kecamatan Telok Sebong dalam angka tahun 2019".

Badan Pusat Statistik, “Kecamatan Senayang dalam angka tahun 2018”

Ikatan Akuntan Indonesia, 2016, "PSAK no.2”, Standar Akuntansi Keuangan.

Ismail, et.al, 2013, "Analisa Kelayakan Usaha Perikanan Laut Kabupaten Kendal", Jurnal Saintek Perikanan vol.8, no.2, 2013, hal. 52-56, Universitas Diponegoro.

Neliyani, et.al, 2014, "Analisis Kelayakan Usaha Perikanan Pukat Cincin di Pelabuhan Perikanan Pantai Lampulo Banda Aceh", Marine Fisheries, vol5, no.2, Nov 2014, ISSN : 2087-4235, Institut Pertanian Bogor.

Rambe, et.al, "Composition of Capchesof Kelong Bilis Fishing Gear Before and After Midnight in The Village Malang Rapat of Sub District Bintan Gunung Kijang Province Islands Riau"

Scott, Jr et.al, 2000, “ Basic Financial Management”, eight edition, Prentice Hall.

Tamarol, Sarapil, 2017, "Analisis Aspek Teknis dan Aspek Ekonomis Pukat Cincin (Mini Purse Seine) yang dioperasikan di Rumpon”, Jurnal IImiah Tindalung, vol 3, no.1, Maret 2017, hal 15-22.

UU no.45 / 2009

Van Horne, Wachowicz, 2007, "Prinsip-Prinsip Manajemen Keuangan”, buku 2 edisi 12, Salemba Empat.

$\underline{\text { www.bri.co.id }}$ 